\begin{tabular}{c}
\hline Review of \\
ECONOMICS \\
and \\
INSTITUTIONS
\end{tabular}

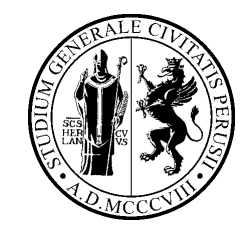

www.rei.unipg.it

\title{
Product and Labour Market Regulations, Production Prices, Wages and Productivity
}

\author{
Gilbert Cette \\ Banque de France, \\ Aix-Marseille School \\ of Economics, \\ CNRS, EHESS
}

\author{
Jimmy Lopez ${ }^{\square}$ \\ Université de Bourgogne- \\ Franche-Comte \\ (LEDI), \\ Banque de France
}

\author{
Jacques Mairesse \\ CREST-ENSAE, \\ Maastricht University \\ (UNU-MERIT), \\ Banque de France, \\ NBER
}

\begin{abstract}
This study is an attempt to evaluate the effects of product and labour market regulations on industry productivity through their various impacts on changes in production prices and wages. In a first stage, the estimation of a regression equation on an industry*country panel, with controls for country*industry and country*year fixed effects, show that multi-factor productivity is negatively and significantly influenced by both indicators of industrial prices from same industry and weighted average of industrial prices from other industries, and by indicators of country wages weighted by industry labour shares for low and high skilled workers. In a second stage, an economic policy simulation of the implications these results on the basis of their calibration by the OECD product and labour market anti-competitive regulation indicators suggests that nearly all countries could expect sizeable gains in multifactor productivity from deregulation reforms.
\end{abstract}

JEL classification: C23, L16, L50, O43, 047

Keywords: Productivity, market regulations, rents

We are grateful to Francesco Venturini and an anonymous referee for their comments. We have also benefitted from suggestions of participants at the various seminars and meetings where previous versions of this paper were presented, in particular the AEA Annual Meeting 2016 (San Francisco), AFSE Conference 2015 (Rennes), AMSE and Banque de France seminars, EcoMod 2016 (Lisbon) and the SEM Conference 2015 (Paris). The views expressed in this paper are those of the authors and do not necessarily reflect those of the institutions they belong to.

Address: Pôle d'Economie et de Gestion, 2 boulevard Gabriel, BP 26611, 21066 DIJON cedex, France (Tel. +33 380395442, Email: jimmy.lopez@u-bourgogne.fr).

\section{Recommended Citation}

Cette, G., Lopez, J., Mairesse J. (2016). Product and Labour Market Regulations, Production Prices, Wages and Productivity. Review of Economics and Institutions, 7(2), Article 1. doi: 10.5202/rei.v7i2.220.

Retrieved from http://www.rei.unipg.it/rei/article/view/220 


\section{Introduction}

A large body of literature investigates the productivity impacts of product and labor market imperfections, and of the anti-competitive regulations establishing and supporting them (see Aghion and Howitt 2009 for a survey). This paper greatly extends the scope of two previous studies by the authors (Bourlès et al., 2013, and Cette et al. 2016) that focus on the 'indirect' productivity impact of non-manufacturing regulations using country*industry panel data. ${ }^{1}$

According to our previous empirical investigations using the OECD regulation indicators, non-manufacturing anticompetitive regulations in industries producing intermediate inputs curb the productivity of industries using these inputs (this effect is called the 'indirect' impact of regulations in this paper). ${ }^{2}$ On a country*industry panel that is basically the same as in the other two previous studies, this new paper allows to assess and compare the relative size of the different channels of direct and indirect impacts of product and labor market regulations on productivity, by considering the effects of these regulations through their various impacts on production prices and wages. The paper also takes advantage of the rich information provided by the OECD regulation indicators, but it does so only indirectly for economic policy calibration and simulation purposes. The originality of our new approach is twofold. First, to our knowledge, it is the first attempt to assess the consequences on productivity of anti-competitive regulations in product and labor markets through their impacts on production prices and wages. ${ }^{3}$ Thus, this paper tests whether the indirect impact of anticompetitive regulations is due to their effects on firm market power. Second, thanks to the use of production prices and wages, it does so by considering in conjunction the six channels through which regulations can impact MFP: direct and indirect influence of product market regulations on rent building in manufacturing and non-manufacturing industries, and direct influence of labor market regulations on the rent sharing process between firms on the one hand and skilled and unskilled workers on the other.

1 This indirect impact on productivity is also investigated by few other studies: (i) Allegra et al. (2004), Forlani (2010) and Arnold et al. (2011) using single country data; (ii) Barone and Cingano (2011) mobilizing cross section data; (iii) Conway et al. (2006) mobilizing country-industry panel data (but these authors did not distinguish between the direct and indirect effects); and (iv) Franco et al. (2016) mobilizing also country-industry panel data and focusing on innovation efficiency using a stochastic frontier analysis. The estimation results of these papers are not directly comparable to Bourlès et al. (2013), and Cette et al. (2016) results, but are qualitatively consistent with them.

2 Bourlès et al. (2013) find also evidence that the indirect impact of anticompetitive product market regulations on productivity is stronger close to the technological frontier, whereas Cette et al. (2016) find that a good part of this indirect impact is transmitted through investments in both R\&D and, to a lesser extent, ICT.

3 Askenazy et al. (2013) rely on similar assumptions and data to analyse the effects of anticompetitive regulations on the country*industry changes in income shares. 
Our approach is theoretically grounded in the model developed by Blanchard and Giavazzi (2003). In their own words, "their model is built on two basic assumptions: monopolistic competition in the goods market, which determines the size of rents; and bargaining in the labor market, which determines the distribution of rents between workers and firm."(ibidem, pp. 879-880). In other words, firms can take advantage of the market power permitted by product market anti-competitive regulations to charge higher production prices and generate rents that they can be kept in the form of increased profits. Workers can also capture in the form of higher wages a share of these rents, which varies with their bargaining power, it largely influenced by labor market regulations. Our empirical framework is an attempt to assess the productivity impact of regulations as mediated by their effects on the changes on production prices and wages. It can be simply explained by the diagram of Figure 1, which we shall now comment.

Figure 1. Diagram of the Overall Framework

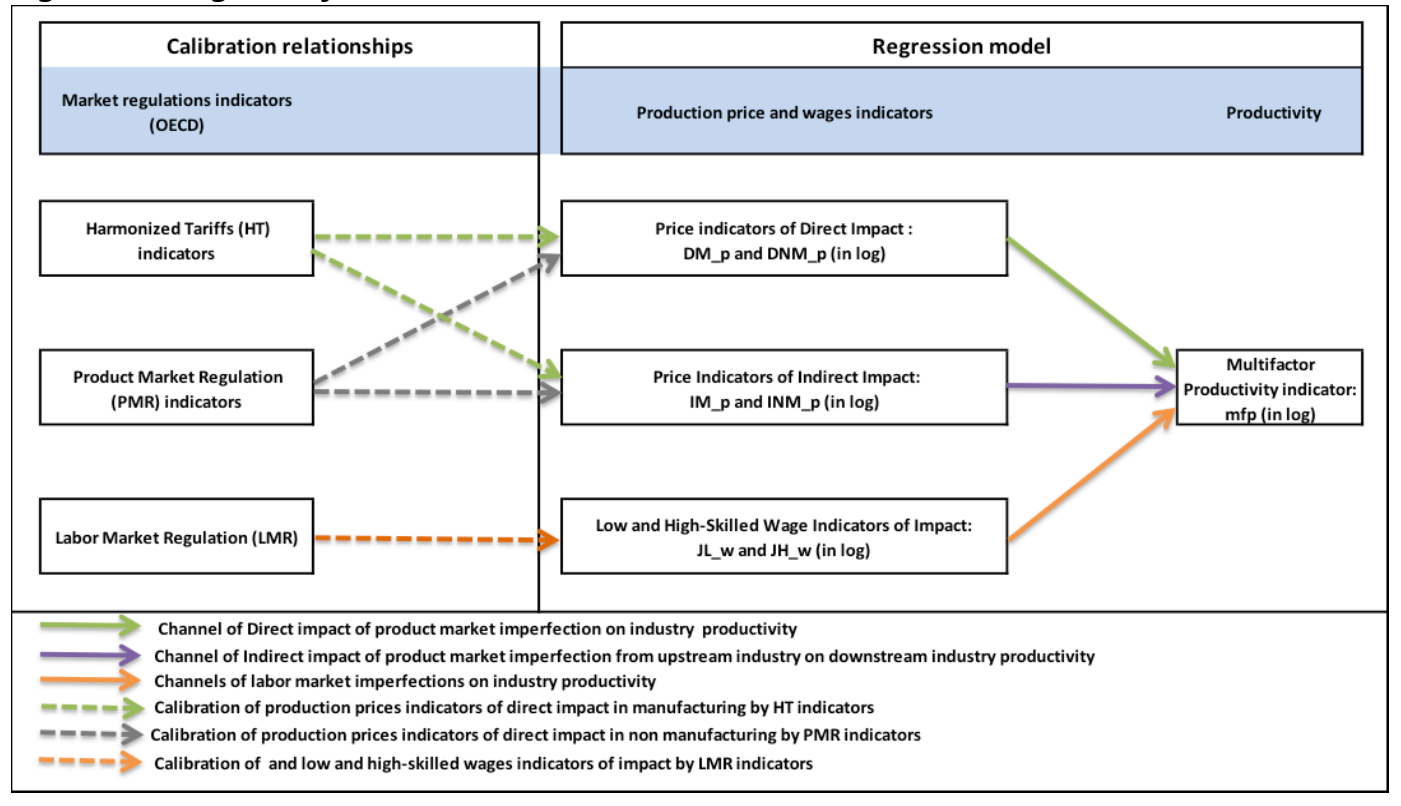

The right side of the diagram outlines the regression equation central to our investigation. It shows the channels by which the six price and wage indicators, key in the analysis, relate to Multifactor Productivity (MFP). The left side of the diagram shows the calibration relationships, which validate our use of six price and wage indicators as proxies of the product and labor market imperfections impacts, and allow us to perform simulations of the MFP gains resulting from structural reforms of product and labor markets, as gauged by the OECD indicators for Non-Manufacturing Regulations (NMR), Harmonized tariffs (HT) and Employment Protection Legislation (EPL).

The regression equation assumes that product market imperfections in an industry generate higher production prices and rents, which have a "direct" impact on MFP in the same industry and an "indirect" impact on 
$M F P$ in other industries. The two price indicators of direct impacts measure the extent to which what we label "Manufacturing" industries and Non-Manufacturing" industries are able to charge relatively high prices. They thus benefit from large rents and have fewer incentives to improve their efficiency and to innovate but also more financial resources to do so. We can thus expect an impact on MFP that could be either negative or positive. A negative sign may a priori seem more likely for nonmanufacturing industries generally sheltered from foreign competition and often protected from national competition by product market regulations. But this may also be true for manufacturing industries when they are protected from foreign competition by high tariff barriers. The two price indicators of indirect impacts are similarly indicative of weaker incentives to improve efficiency and to innovate by "downstream" industries when the rents they can generate are appropriated by "upstream" industries that have market power and can charge them relatively high prices for the intermediate inputs they must use. In this case, however, the expected impact on $M F P$ is unambiguously negative. Again and for the same reasons this should be more likely when the upstream industries are non-manufacturing industries than manufacturing industries. Our regression equation also assumes that, in conjunction with product market imperfections in an industry, labor market imperfections may result in higher wages and lower profits, entailing a negative impact on the industry MFP. Employment protection legislation, professional agreements and standards, shortage of qualified workers, etc., contribute to higher wages, implying that rents, which could have been fully appropriated by firms' owners and shareholders, are shared with workers. In turn, firms have fewer incentives and financial resources to improve their efficiency and to innovate. We can thus expect that the low- and high-skilled wage indicators have a negative impact on MFP. Since high-skilled workers have a stronger bargaining power than low-skilled workers, it is also likely that the negative impact would be larger for the former than the latter.

In Section 2, we describe our country*industry panel data sample, define in detail the six production price and wage impact indicators, and discuss in depth the econometric specification of our regression model. Our main estimation results are presented and discussed in Section 3. They show that the estimated coefficients of our six impact indicators are all negative and are both statistically and economically significant. In Section 4 we consider an illustrative policy simulation based on these results and on their calibration by the OECD product and labor market anti-competitive regulation indicators, which suggests that nearly all countries could expect sizeable gains in multifactor productivity over the years from an economic policy of deregulation reforms. Section 5 offers a short conclusion, stressing the plausibility of our results but also their fragility and limitations, largely inherent in the aggregate nature of our framework and supporting data. 


\section{Regression Model and Data}

Our analysis is based on an unbalanced country*industry*year panel data sample covering fourteen OECD countries and eighteen industries: thirteen mainly in "Manufacturing" and five mainly in "NonManufacturing". Due to the lack of data for several countries and/or sectors in the earlier years, it is relatively unbalanced ranging for each country*industry time series from 1987 to 2007 at maximum, six years at minimum and about 12 years on average. The fourteen countries are: Austria, Canada, Czech Republic, Denmark, Finland, France, Germany, Italy, Japan, the Netherlands, Spain, Sweden, the United Kingdom and the United States. For the sake of convenience, "Manufacturing" refers here to: food products, textiles, wood products, paper, chemicals products, non-metallic mineral products, metal products, machinery not elsewhere classified (n.e.c.), electrical equipment, transport equipment, manufacturing n.e.c., as well as construction and hotels \& restaurants; while "non-manufacturing" refers to: energy, transport \& communication, retail distribution, banking services and professional services. Overall, our panel data sample contains 2,820 observations, when we exclude the United States that we have taken in our analysis as the country of reference to control for unobserved technical changes at the industry level.

Production prices, intermediate consumption and data used to calculate MFP come mainly from OECD databases, while wages by skill level and physical investments by assets (used to calculate MFP) come from the EUKLEMS database. The regulation indicators that we use to assess the economic significance of our results and to calibrate simulations of the potential impacts of structural reforms are constructed on the basis of the OECD indicators for NMR, HT and EPL. Appendices A and B provide detailed information on the panel composition, the construction of variables and the OECD indicators. They also show some simple descriptive statistics. As shown in the Diagram, in our regression model, MFP expressed in logarithm and noted as $m f p_{c i t}$ for country $c$, industry $i$ and year $t$, is related to four impact indicators based on production price data, two "direct" impact indicators $D M_{-} p_{c i t}$ and $D N M_{-} p_{c i t}$ for manufacturing industries and non-manufacturing industries respectively, and two "indirect" impact indicators $I M \_p_{\text {cit }}$ and $I N M_{-} p_{\text {cit }}$ for impacts on "downstream" industries originating from "upstream" manufacturing and nonmanufacturing industries respectively. They also consist of two impact indicators based on low-skilled $(L)$ and high-skilled $(H)$ wage data noted $J L_{-} w_{c i t}$ and $J H_{-} w_{c i t}$. The direct country*industry price impact indicators are simply defined as:

$$
D M \_p_{c i t}=p_{c i t} \text { with } i \in M \text { and } D N M \_p_{c i t}=p_{c i t} \text { with } i \in N
$$

where $p_{\text {cit }}$ is the logarithm of the production price index relative to the GDP price index, for country $c$, industry $i$ and year $t$, normalized to be equal to one in year 2000 (with $i \in M$ for the manufacturing industries 
and $i \in N M$ for the non-manufacturing industries). Because of the aggregate nature of our panel sample, the price direct impact coefficients we can expect to estimate with good precision are two average country*industry elasticities (not separate elasticities by country or industry, or country ${ }^{*}$ industry).

The country ${ }^{*}$ industry price indirect impact indicators are composite indicators of the same production prices but for the upstream industries, and are defined as:

$$
I M \_p_{c i t}=\sum_{j \in M \& j \neq i} p_{c j t} \cdot U S E_{i}^{j} \quad \text { and INM_p } p_{c i t}=\sum_{j \in N M \& j \neq i} p_{c j t} \cdot U S E_{i}^{j}
$$

where $U S E_{i}^{j}$ is the intensity-of-use of intermediate inputs, defined as the ratio of the intermediate consumption from industry $j$ to industry $i$ over the production of industry $i$ and measured on the basis of the 2000 input-output table for the USA, taken as country of reference in our analysis. Here also, the coefficients that can be precisely estimated are two average country*industry elasticities with respect to the manufacturing and non-manufacturing industries. For that purpose, interacting the log upstream industry price with the intermediate input intensity-of-use ratio is an appropriate way to take into account the intrinsic heterogeneity of their potential impact on downstream multifactor productivity, assuming that the higher this ratio, the higher the impact of a given change in upstream industry price. Note also that we prefer to use the USA 2000 input-output table as a weighting fixed reference in the computation of the intensity-of-use ratios to avoid endogeneity biases that might arise from potential correlations between the country*industry changes in such ratios and productivity. For a similar reason we also exclude the intra-industry intermediate consumption in the computation. The low- and high-skilled country*industry wage impact indicators are defined as:

$$
J L_{-} w_{c i t}=w_{c t}^{L} \cdot S H A R E_{i}^{L} \quad \text { and } \quad J H_{-} w_{c i t}=w_{c t}^{H} \cdot S H A R E_{i}^{H}
$$

where $w_{c t}^{L}$ and $w_{c t}^{H}$ are the country's real wage index, in logarithms, for the low- and high-skilled workers of country $c$, and $S H A R E_{i}^{L}$ and $S H A R E_{i}^{H}$ are the corresponding shares of labour costs in the production value of industry $i$ for the USA in 2000. As in the case of the price direct and indirect impact indicators, the coefficients we can hope to estimate accurately enough are two average country*industry elasticities. Similarly to what we do to construct the price indirect impact indicators, we deem appropriate to interact the log country's low- and high-skilled wages with the corresponding labor costs shares in production at the industry level for the USA in 2000, assuming that the higher these changes, the higher the impact of a given change of a given change in low- and high-skill industry wage. To also avoid potential endogeneity biases we rely on the USA 2000 industry shares as fixed reference. Note finally that since we found that 
the estimated elasticities of the indicators based on separate low- and medium-skilled wages were not statistically different, we pool them for the sake of greater precision as one indicator, to which we simply refer here as the low-skilled wage impact indicator.

Finally, our first regression specification is the following:

$$
\begin{gathered}
m f p_{c i t}=\alpha \cdot D M_{p_{c i(t-1)}}+\beta \cdot D N M_{p_{c i(t-1)}}+\gamma \cdot I M_{p_{c i(t-1)}} \\
+\delta \cdot I N M_{-} p_{c i(t-1)}+\lambda \cdot J L_{-} w_{c i(t-1)}+\mu \cdot J H_{-} w_{c i(t-1)}+\theta \cdot m f p_{U S i(t-1)} \\
+\eta_{c}+\eta_{i}+\eta_{t}+\eta_{c i}+\eta_{c t}+\varepsilon_{c i t}
\end{gathered}
$$

In addition to the six prices and wage impact indicators defined above, we included the log USA multifactor productivity for industry $i$ and year $(t-1) m f p_{U S i(t-1)}$ in order to control mainly for exogenous technical changes at the industry level. We chose the USA, which is at the world productivity frontier in most industries, as an appropriate reference country for our analysis. $\alpha, \beta, \gamma, \delta, \lambda$ and $\mu$ are our elasticity parameters of interest. $\varepsilon_{c i t}$ is the idiosyncratic random error of the regression. $\eta_{c}, \eta_{i}$ and $\eta_{t}$ denote the one-way country, industry and year fixed effects that are usually included in regression models estimated on panel data samples such as ours in order to control for distinctive country, industry or period characteristics, which could affect the estimates of the parameters of interest. $\eta_{c i}$ and $\eta_{c t}$ stand for two-way country*industry and country* ${ }^{*}$ ear fixed effects. We present also estimation results adding industry* year $\eta_{i t}$ to the set of fixed effects. The fixed effects are an important component in our regression specification for reasons we shall make clear in explaining our estimation method.

As a variant of our regression specification (1), we have also considered the following simpler specification (2):

$$
\begin{aligned}
& m f p_{c i t}=\alpha \cdot D_{p_{c i(t-1)}}+\gamma \cdot I_{p_{c i(t-1)}}+\lambda \cdot J_{w_{c i}(t-1)} \\
& +\theta \cdot m f p_{U S i(t-1)}+\eta_{c}+\eta_{i}+\eta_{t}+\eta_{c i}+\eta_{c t}+\varepsilon_{c i t}
\end{aligned}
$$

where $D_{-} p_{c i t}, I_{-} p_{c i t}, J_{-} w_{c i t}$ are respectively the production price indicators of direct and indirect impacts pooled over manufacturing and non-manufacturing industries and the wage indicators of impact pooled over low- and high-skills.

\section{Estimation and Main Results}

Before presenting our main results, we must explain how they have been estimated to take care of various sources of potential biases, and in particular why we entered two-way country-industry and country-year fixed effects in our regression model. The purpose of including $\eta_{c i}$ and $\eta_{c t}$ is to correct for the biases which could be due to the omission of relevant explanatory variables and also to attenuate biases potentially arising 
from other sources of endogeneity. It does so at the cost of reducing the variability of the data on which our estimates are actually based and at the risk of exacerbating downward biases from measurement errors in variables. ${ }^{4}$ Actually, entering $\eta_{c i}$ in regression (1) is a necessity in the present context since our price and wage indicators do not measure absolute levels of price or wage but are computed from price and wage indices normalized to be equal to 1 in a given reference year (in our case 2000). The evidence on which we rely for estimation is thus only based on the within country*industry changes over time of the variables in the regression, implying an important cut back in their standard-deviation conditional on $\eta_{c i}$ (as shown in Table A1.1 of Appendix 1). Including also the country*year fixed effects $\eta_{c t}$ entails an additional reduction of variability, especially large for the price indirect impact and wage impact indicators. It is, however, a useful precaution protecting from a variety of sources of potential estimation biases, such as differences in country multifactor productivity not related to product or labor market imperfections (and not captured by the presence of $m f p_{U S}$ ), and simultaneity biases due to changes in prices and wages in response to country productivity shocks. It is also possible to go one more step further and substitute industry* ${ }^{*}$ ear fixed effects $\eta_{i t}$ to $m f p_{U S}$ to control more fully for industry technical changes and other variation in industry multifactor productivity. Notably, the inclusion of $\eta_{i t}$ may offset the endogeneity bias resulting from the over-time correlation of competition changes within countries and across industries. This issue may concern particularly industries such as energy, transport and communications in which international agreements and regulations are widespread. We present estimates with and without industry ${ }^{*}$ year fixed effects. The inclusion of these fixed effects would be, however, at the cost of reducing even more the identifying variability of the data, and it would be at the risk of exacerbating downward biases from measurement errors in variables. As discussed in Cette et al. (2016), we can view the regression results obtained when including only the country*year fixed effects $\eta_{c t}$ or both the country*year and industry*year fixed effects $\left(\eta_{c t}\right.$ and $\left.\eta_{i t}\right)$ as providing respectively upper and lower bound estimates, but we can also put some more confidence on the upper bound estimates and focus on them as our preferred estimates. Besides controlling for interacted fixed effects in our regression, we prefer not to rely on the Ordinary Least Squares (OLS) estimator but to implement the Dynamic OLS (DOLS) estimator proposed by Stock and Watson (1993). ${ }^{5}$ This estimator has the advantage to make sure that the estimated elasticities are not biased by short-term correlations between the variables and the idiosyncratic error $\varepsilon_{c i t}$, and that we can consider them as long-term parameters. When the variables used are non-stationary, the

4 See Griliches and Mairesse (1998) who document and strongly stress such risk in the context of the identification of production function on panel data.

5 We have found that it is enough to keep only one lead and one lag of these first differences. 
DOLS estimator eliminates these short-term correlations by including in the regressions leads and lags of the first differences of the potentially endogenous explanatory variables. ${ }^{6}$ Finally, note that we have lagged in regression (1) all explanatory variables by one year as another safeguard to avoid spurious contemporaneous correlations with productivity changes. Our main estimation results are given in Tables 1 and 2, with the estimated impact elasticities in column 5 of Table 1 for the specification (2) and of Table 2 for the more detailed specification (1).

Table 1. Main Estimates for Less Detailed Regression Specifications

\begin{tabular}{|c|c|c|c|c|c|c|c|}
\hline LHS: MFP ( $m f p)$ & (1) & (2) & (3) & (4) & (5) & (6) & (7) \\
\hline Estimator & \multicolumn{6}{|c|}{ DOLS (with one lead and one lag) } & OLS \\
\hline US MFP $\left(m f p^{u s}\right)$ & $\begin{array}{c}0.688 * * * \\
{[0.014]}\end{array}$ & $\begin{array}{c}0.821 * * * \\
{[0.013]}\end{array}$ & $\begin{array}{c}0.704 * * * \\
{[0.014]}\end{array}$ & $\begin{array}{c}0.808 * * * \\
{[0.012]}\end{array}$ & $\begin{array}{c}0.720 * * * \\
{[0.014]}\end{array}$ & - & $\begin{array}{c}0.687^{* * *} \\
{[0.013]}\end{array}$ \\
\hline Direct prices $\left(D \_p\right)$ & $\begin{array}{c}-0.513 * * * \\
{[0.034]}\end{array}$ & & $\begin{array}{c}-0.523 * * * \\
{[0.033]}\end{array}$ & & $\begin{array}{c}-0.441^{* * *} \\
{[0.033]}\end{array}$ & $\begin{array}{c}-0.248 * * * \\
{[0.030]}\end{array}$ & $\begin{array}{c}-0.460 * * * \\
{[0.031]}\end{array}$ \\
\hline Indirect prices (I_p) & & $\begin{array}{c}-0.486 * * * \\
{[0.074]}\end{array}$ & $\begin{array}{c}-0.546 * * * \\
{[0.070]}\end{array}$ & & $\begin{array}{c}-0.479 * * * \\
{[0.068]}\end{array}$ & $\begin{array}{c}-0.278 * * * \\
{[0.090]}\end{array}$ & $\begin{array}{c}-0.392 * * * \\
{[0.064]}\end{array}$ \\
\hline $\begin{array}{l}\text { Wage impact indicator } \\
\left(J_{-} w\right)\end{array}$ & & & & $\begin{array}{c}-2.338 * * * \\
{[0.165]}\end{array}$ & $\begin{array}{c}-2.091 * * * \\
{[0.170]}\end{array}$ & $\begin{array}{l}-0.499 * \\
{[0.285]}\end{array}$ & $\begin{array}{c}-1.650 * * * \\
{[0.157]}\end{array}$ \\
\hline Observations & 2820 & 2820 & 2820 & 2820 & 2820 & 2820 & 2820 \\
\hline R-squared & 0.779 & 0.76 & 0.785 & 0.774 & 0.798 & 0.872 & 0.783 \\
\hline \multicolumn{8}{|l|}{ Fixed effects } \\
\hline Country*Industry & Y & $\mathrm{Y}$ & Y & $\mathrm{Y}$ & Y & Y & Y \\
\hline Country*Year & Y & $\mathrm{Y}$ & Y & $\mathrm{Y}$ & $\mathrm{Y}$ & Y & $\mathrm{Y}$ \\
\hline Industry*Year & $\mathrm{N}$ & $\mathrm{N}$ & $\mathrm{N}$ & $\mathrm{N}$ & $\mathrm{N}$ & $\mathrm{Y}$ & $\mathrm{N}$ \\
\hline
\end{tabular}

*** Significant at 1\%; ** significant at 5\%; *significant at $10 \%$. Standard errors between brackets. All the explanatory variables are one year lagged.

Columns 1 to 4 of these two tables show the corresponding estimated elasticities for specifications in which the price direct and indirect impact indicators and the wage impact indicators are introduced sequentially. Column 6 shows the robustness of the estimation results to the inclusion of industry*year fixed effects and column 7 to the use of the OLS estimator instead of the DOLS one.

Focusing first on the estimates for the full specifications (column 5) of regression speciation (1) and (2), we see that the estimated elasticities for all impact indicators are negative and statistically very significant, with standard errors roughly proportional to their size (i.e. with comparable Student $\mathrm{t}$-statistics and relative precision).

6 To support our long-term interpretation of our estimation results and our reliance on the DOLS estimators, we performed Levin et al. (2002) and Im et al. (2003) panel data unit-root tests on our dependent and explanatory variables and Pedroni $(1999,2004)$ panel data cointegration tests. All the unit-root tests confirm that our variables are I(1), whereas the cointegration tests are somewhat less clear-cut, with four out of seven rejecting the no-cointegration null hypothesis. However, because of the short time dimension of our panel data sample, the power of these tests is relatively weak. 
Table 2. Main Estimates for Less Detailed Regression Specifications

\begin{tabular}{|c|c|c|c|c|c|c|c|}
\hline \multirow{2}{*}{$\begin{array}{c}\text { LHS: MFP }(\boldsymbol{m f p}) \\
\text { Estimator }\end{array}$} & (1) & (2) & (3) & (4) & (5) & (6) & (7) \\
\hline & \multicolumn{6}{|c|}{ DOLS (with one lead and one lag) } & OLS \\
\hline \multirow[t]{2}{*}{ US MFP $\left(m f p^{u s}\right)$} & $0.713^{* * *}$ & $0.818 * * *$ & $0.731 * * *$ & $0.835^{* * *}$ & $0.756 * * *$ & - & $0.717^{* * *}$ \\
\hline & {$[0.015]$} & {$[0.012]$} & {$[0.014]$} & [0.013] & {$[0.015]$} & & {$[0.014]$} \\
\hline \multicolumn{8}{|l|}{ Direct prices in } \\
\hline Manufacturing & $-0.481 * * *$ & & $-0.434 * * *$ & & $-0.379 * * *$ & $-0.130 * * *$ & $-0.406 * * *$ \\
\hline \multicolumn{8}{|l|}{ industries } \\
\hline (DM_p) & [0.037] & & [0.037] & & [0.037] & [0.033] & {$[0.034]$} \\
\hline Non-Manuf. Industries & & $-1.051 * * *$ & $-1.072 * * *$ & & $-0.827 * * *$ & $-0.719 * * *$ & $-0.785 * * *$ \\
\hline (DNM_p) & & {$[0.085]$} & {$[0.088]$} & & {$[0.090]$} & {$[0.080]$} & {$[0.080]$} \\
\hline \multicolumn{8}{|l|}{ Indirect prices from } \\
\hline Manufacturing & $-0.488 * * *$ & & $-0.475^{* * *}$ & & $-0.446 * * *$ & $-0.271 * * *$ & $-0.359 * * *$ \\
\hline \multicolumn{8}{|l|}{ industries } \\
\hline$\left(I M \_p\right)$ & {$[0.072]$} & & {$[0.070]$} & & [0.069] & [0.091] & {$[0.064]$} \\
\hline Non-Manuf. Industries & & $-9.361 * * *$ & $-7.490 * * *$ & & $5.060 * * *$ & -0.798 & $-4.838 * * *$ \\
\hline (INM_p) & & [0.852] & [0.863] & & [0.898] & [0.872] & {$[0.844]$} \\
\hline \multicolumn{8}{|c|}{ Country wages * industry labor share } \\
\hline High Skills & & & & $-4.239 * * *$ & $-3.043 * * *$ & $-2.162 * * *$ & $-2.412 * * *$ \\
\hline$\left(J H \_w\right)$ & & & & {$[0.320]$} & [0.329] & {$[0.477]$} & {$[0.292]$} \\
\hline Low Skills & & & & $-2.037 * * *$ & $-1.743 * * *$ & -0.112 & $-1.327 * * *$ \\
\hline$\left(J L \_w\right)$ & & & & {$[0.223]$} & {$[0.215]$} & [0.339] & {$[0.202]$} \\
\hline Observations & 2820 & 2820 & 2820 & 2820 & 2820 & 2820 & 2820 \\
\hline R-squared & 0.777 & 0.773 & 0.792 & 0.779 & 0,804 & 0.877 & 0.788 \\
\hline \multicolumn{8}{|l|}{ Fixed effects } \\
\hline Country*Industry & Y & Y & Y & Y & Y & Y & Y \\
\hline Country*Year & Y & Y & Y & Y & Y & Y & Y \\
\hline Industry*Year & $\mathrm{N}$ & $\mathrm{N}$ & $\mathrm{N}$ & $\mathrm{N}$ & $\mathrm{N}$ & $\mathrm{Y}$ & $\mathrm{N}$ \\
\hline
\end{tabular}

*** Significant at $1 \% ;{ }^{* *}$ significant at $5 \% ;{ }^{*}$ significant at $10 \%$. Standard errors between brackets. All the explanatory variables are one year lagged.

We find very large and significant differences between the manufacturing and non-manufacturing direct and indirect price impact estimated elasticities and the low and high-skill wage impact estimated elasticities: they are twice for $D N M_{\_} p$ than for $D M_{\_} p$ (about 0.8 versus 0.4 ), ten times higher for $I N M_{-} p$ than for $I M_{-} p$ (about 5.0 versus 0.5 ), and almost twice also for $J H_{-} w$ than for $J L_{-} w$ (3.0 versus 1.7$)$.

Looking now at the robustness of these estimates to omission bias, we find that the three pooled impact elasticities are only moderately decreasing whenever another indicator is included, but not the point of becoming statistically different. The six detailed impact elasticities appear less robust. In particular the elasticity of $I N M_{-} p$ varies from -5.1 , if estimated only with $I M \_p$, to -9.4 if estimated with all other indicators. Similarly the elasticity of $J H_{-} w$ varies from -3.0 to -4.2. All six elasticities remain negative and statistically very significant, and on the whole satisfactory.

Concerning the estimate robustness to the inclusion of industry ${ }^{*}$ year fixed effects $\eta_{i t}$, we find that, in spite of the inherent uncertainties of our analysis, our estimates of the prices and wages impact indicators elasticities appear fairly robust overall in specification (1) and (2). When we con- 
trol for both $\eta_{c t}$ and $\eta_{i t}$, the estimated elasticities are significantly smaller, but all elasticities are negative as expected and most are in fact not statistically different from the specification without $\eta_{i t}$ at the $5 \%$ or $10 \%$ confidence level (see column 6). However, the detailed estimates of specification (2) appear less stable than the pooled ones of specification (1): the price indirect impact elasticity from non-manufacturing and the low-skill wage impact elasticity, which stand out as very much reduced, are no more statistically significant from zero (even at a $10 \%$ confidence level). Such extreme reduction with loss of statistical significance is most likely related to the very small residual identifying variability of the two corresponding price and wage impact indicators $I N M \_p$ and $J L_{-} w$ and possibly reflects large attenuation biases due to the exacerbation of measurement errors in these indicators.

Finally, columns 7 of Tables 1 and 2 show the estimate robustness to the use of the OLS instead of DOLS estimator. Although the choice of the DOLS estimator is confirmed by means of a Hausman test, we can see that the OLS and DOLS estimates are very close for all elasticities.

\section{Simulation of the Impact of Structural Reforms}

The estimation results for regression (1) appear quite satisfactory, i.e. with productivity elasticities of all our price and wage indicators of the expected sign, statistically significant and reasonably robust. However, they cannot unambiguously be interpreted in terms of productivity impacts of anti-competitive regulations in the product and labor markets, and thus cannot directly be used to assess the potential effects of structural reforms in these markets. Moreover, despite the great care we have taken to avoid specification error biases in estimating our regression model, it is indeed important to confirm that our production price and wage indicators indirectly capture the impacts of regulations. We address these two issues by calibrating them in relation to the OECD NMR and HT indicators on the one hand and to the OECD EPL indicators on the other hand. As documented in some details in Appendix 2, the OECD indicators are constructed on the basis of very detailed information on laws, rules and market, country and industry settings, and they have thus the advantage of being directly related to underlying policies and they can be considered, at least to a major extent, to be exogenous to productivity developments.

The estimation results of the calibration are presented in Table 3 . We have performed four distinct OLS projections on the OECD indicators: (i) the country ${ }^{*}$ industry changes on production prices in non-manufacturing industries on the NMR indicators (column 1); (ii) the country*industry changes on production prices in manufacturing industries on the $H T$ indicators (column 2); the country changes in low-skilled wages on the EPL indicator (column 3); and (iv) the country changes in high-skilled wages on the EPL indicator (column 4). The projection coefficients estimates we find corroborate our hypotheses that changes in production 


\section{Figure 2: Simulated Long-term Impacts on MFP from the Adoption of the Lightest} Practices by Country

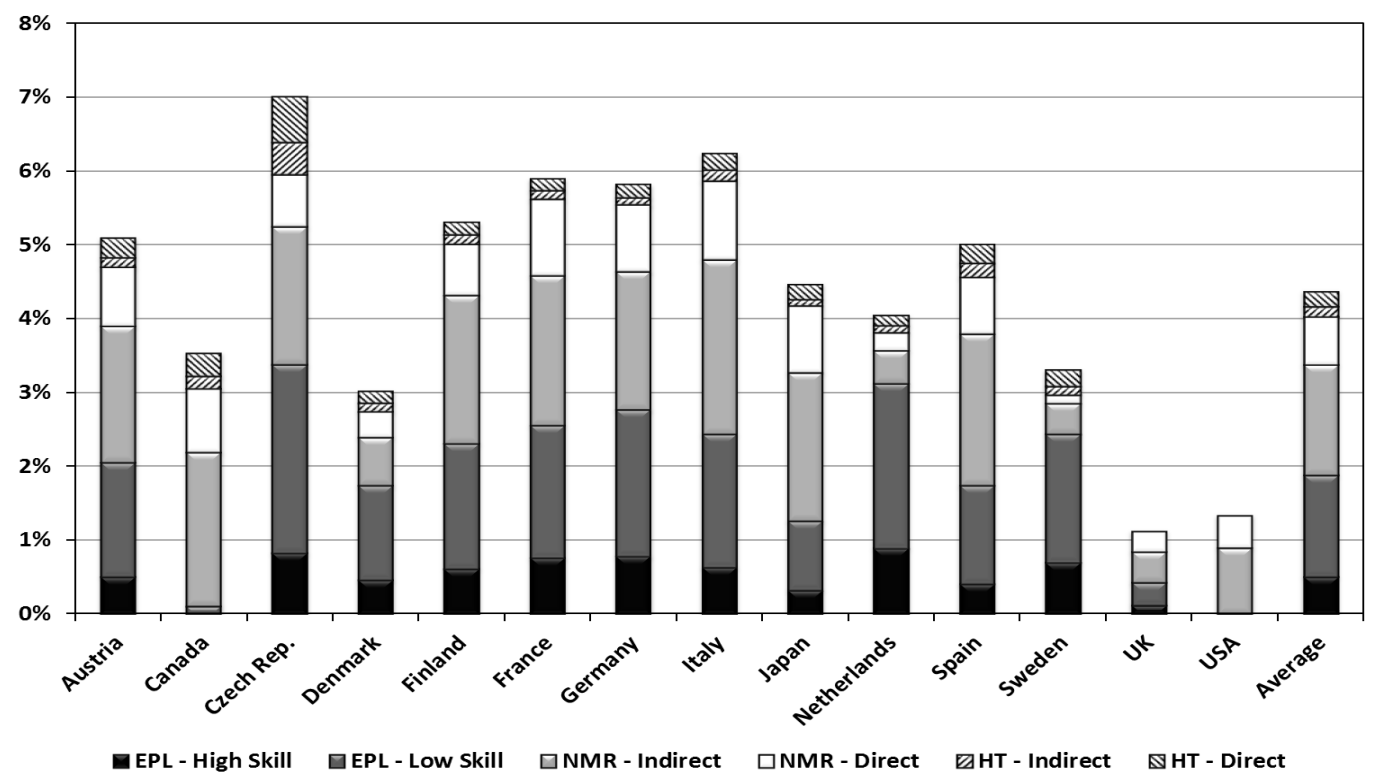

EPL - High-Skilled and EPL - Low-Skilled: Long-run impacts through high and low-skilled wages, respectively.

NMR - Indirect and NMR - Direct: Long-run indirect and direct impacts through production prices in non-manufacturing industries, respectively.

$\boldsymbol{H T}$ - Indirect and $\boldsymbol{H T}$ - Direct: Long-run indirect and direct impacts through production prices in manufacturing industries, respectively.

We see that the average MFP long-term gains are of about $4.4 \%$, but that they vary broadly across countries, depending on the initial regulation levels, from $1.1 \%$ in the UK to $7.0 \%$ in the Czech Republic. The regulatory components of these gains differ widely across countries from one another in absolute size but are close enough in relative terms. The average MFP gains from product market reforms amount to $2.5 \%$, and they arise for $60 \%$ and $26 \%$ from respectively the indirect and direct impacts of the $N M R$ and $H T$ reforms in non-manufacturing industries, and for only about $6 \%$ and $8 \%$ from respectively the indirect and direct impacts of these reforms in manufacturing industries. The average gains from the EPL reforms are of about $2.0 \%$, resulting for $75 \%$ and $25 \%$ from respectively the low-skilled and high-skilled labor market reforms. It is also interesting to point out the positive correlations between the size of the simulated MFP gains from the $H T$ and EPL reforms and from the NMR and EPL reforms: respectively 0.26 and 0.21 as computed over fourteen countries. This is significant evidence of the complementary linkage between the productivity impacts of regulations on the product and labor markets that is stressed in Blanchard and Giavazzi (2013).

The average and country simulated MFP impacts from a sudden shift to the lightest regulatory practices shown in Figure 2 are long term gains. As 
also detailed in Appendix 3, on the basis of a complementary approximate analysis of the respective adjustments of the changes in $M F P$, production prices and wages and OECD indicators, we can have an idea of the overall speed of evolution to the long-term equilibrium. The results are illustrated by the graphs in Figure 3 for the five following large European countries: France, Germany, Italy, Spain and the UK. They suggest that on average about $30 \%$ of the long-term MFP gains could be achieved after six years on average.

Figure 3. Simulated Evolution of Impacts on MFP from the Adoption of the Lightest Practices for France, Germany, Italy, Spain and the United Kingdom

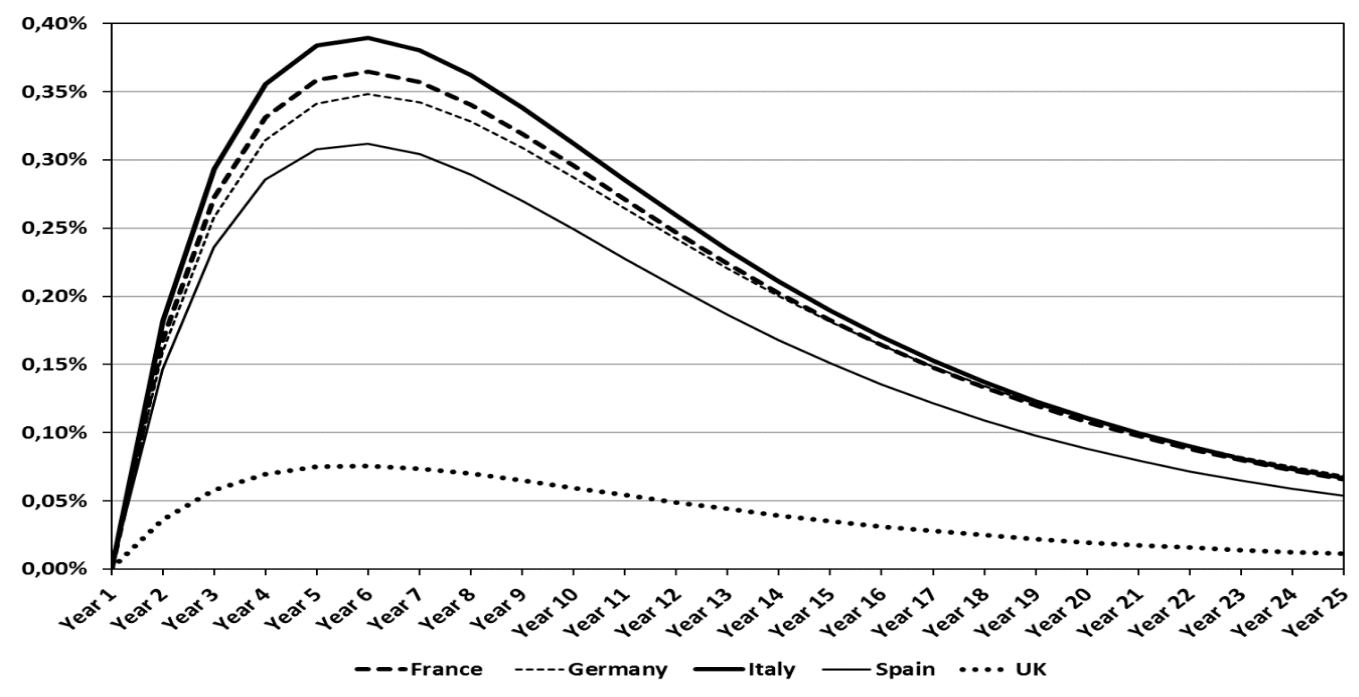

\section{Conclusions}

This study is an attempt to assess the productivity consequences of anti-competitive regulations in product and labor markets by investigating them through the lens of an analysis of the relationships between changes in production prices and wages and changes in multifactor productivity. In our analysis, production prices and wages are indicative of rent building and sharing processes, which impede productivity in different ways and to different extents, and which stem from market imperfections as gauged by the OECD product and labor market regulations indicators. The results are encouraging notwithstanding the great difficulties of the approach and limitations of relying on a macroeconomic country*industry panel. Two simulations, respectively ex-post and ex-ante, based on these results suggest that nearly all countries, particularly European countries, can expect significant gains in multifactor productivity over the years from economic policies reforming anticompetitive regulations on the product and labor markets.

Our estimates and simulations suffer clearly from various weaknesses, due in particular to the data limitation, with implications of course on the econometric methods implemented. They should be taken with particular 
caution and the policy indications that they suggest considered as tentative. In particular, the ex-ante simulation of an extreme, hypothetical of a program of product and labor market reforms consisting in the immediate adoption of country lightest regulation practices must only be viewed as illustrative. We also do not consider in our analysis the great institutional, political and social difficulties that the implementation of such ambitious structural reform programs usually encounters.

We can stress, however, that the evidence concerning the indirect impact of product market regulatory changes in non-manufacturing, which is strongest in our present results analysis, is very much consistent with our previous two evaluations based on an approach largely different in important respects from the one followed here (see Bourlès et al., 2013, and Cette et al. 2016). We can also mention that a number of historical country experiences seem to confirm that ambitious structural reform programs implemented over the last decades have had very large multifactor productivity impacts. This is the case of the reform programs implemented in the Netherlands in the early 1980 or in Australia, Canada and Sweden in the early 1990 that have been followed in the subsequent decade by a much faster growth in multifactor productivity (see Bergeaud et al. 2014).

\section{References}

Aghion, P., Howitt, P., 2009. The Economics of Growth. MIT Press, Cambridge, Massachusetts.

Allegra, E., Forni, M., Grillo, M., Magnani, L., 2004. Antitrust Policy and National Growth: Some Evidence from Italy. Giornale degli Economisti e Annali di Economia 63(1), 69-86.

Arnold, J., Javorcik, B., Mattoo, A., 2011. Does Services Liberalization Benefit Manufacturing Firms?. Journal of International Economics 85(1), 136-146.

Askénazy, P., Cette, G., Maarek, P., 2013. Rent Building, Rent Sharing: A Panel Country-Industry Empirical Analysis. Banque de France Working Paper Series 369.

Barone, G., Cingano, F., 2011. Service Regulation and Growth: Evidence from OECD Countries. The Economic Journal 121(555), 931-957.

Bergeaud, A., Cette, G., Lecat, R., 2014. Productivity Trends from 1890 to 2012 in Advanced Countries. Banque de France Working Paper Series 475. 
Blanchard, O., Giavazzi, F., 2003. Macroeconomic Effects of Regulation and Deregulation in Goods and Labor markets. The Quarterly Journal of Economics 118, 879-907.

Bourlès, R., Cette, G., Lopez, J., Mairesse, J., Nicoletti, G., 2013. Do Product Market Regulations in Upstream Sectors Curb Productivity Growth? Panel Data Evidence for OECD Countries. The Review of Economics and Statistics 95(5), 1750-1768.

Cette, G., Lopez, J., Mairesse, J., 2016. Upstream Product Market Regulations, ICT, R\&D and Productivity. Review of Income and Wealth, DOI: 10.1111 / roiw.12252.

Chiara, F., Pieri, F., Venturini, F., 2016. Product Market Regulation and Innovation Efficiency. Journal of Productivity Analysis 45(3), 299-315.

Conway, P., de Rosa, D., Nicoletti, G., Steiner, F., 2006. Product Market Regulation and Productivity Convergence. OECD Economic Studies 43(2), 39-76.

Forlani, E., 2010. Competition in the Service Sector and the Performances of Manufacturing Firms: Does Liberalization Matter?. CESifo Working Paper Series 2942.

Griliches, Z., Mairesse, J., 1998. Production Functions: The Search for Identification. In: Ström, S., (Eds.), Cambridge University Press, Econometrics and Economic Theory in the 20th Century: The Ragnar Frish Centennial Symposium, pp. 169-203.

Im, K., Pesaran, H., Shin, Y., 2003. Testing for Unit Roots in Heterogeneous Panels. Journal of Econometrics 115(1), 53-74.

Levin, A., Lin, C.-F., Chu, J., 2002. Unit Root Tests in Panel Data: Asymptotic and Finite-Sample Properties. Journal of Econometrics 108(1), 1-24.

Mairesse, J., 1990. Time-series and Cross-sectional Estimates on Panel Data: Why Are They Different and Why Should They Be Equal ?. In: Hartog, J., Ridder, G., Theeuwes, J., (Eds.), Panel Data and Labor Market Studies. Amsterdam, North-Holland, pp. 81-95.

Pedroni, P., 1999. Critical Values for Cointegration Tests in Heterogeneous Panels with Multiple Regressors. Oxford Bulletin of Economics and Statistics 61(0), 653-670.

Pedroni, P., 2004. Panel Cointegration: Asymptotic and Finite Sample Properties of Pooled Time Series Tests with an Application to the PPP Hypothesis. Econometric Theory 20(3), 597-625. 
Stock, J., Watson, M., 1993. A Simple Estimator of Cointegrating Vectors in Higher Order Integrated Systems. Econometrica 61(4), 783-820. 


\section{Appendix 1. Study Sample and Main Variables}

\section{A1.1 Study Sample}

Our study sample is an unbalanced country-industry panel dataset of 2,812 observations from 1987 to 2007, which have been assembled from several sources of data, primarily the STAN OECD data base and which we have already used in our two previous studies (Bourlès et al. 2013, and Cette et al. 2016). For the purpose of this analysis we had to complete it as mainly concerns the production prices and wages information. It covers fourteen countries (Austria, Canada, Czech Republic, Denmark, Finland, France, Germany, Italy, Japan, the Netherlands, Spain, Sweden, the United Kingdom and the United States) and eighteen industries, which we pooled in two groups of industries delineated mainly for reasons of congruence with the OECD regulation indicators $H T$ and NMR (see Appendix 2). The first group, referred as Manufacturing, consists of thirteen industries, eleven of which are properly in manufacturing: food products, textiles, wood products, paper, chemicals products, non-metallic mineral products, metal products, machinery non elsewhere classified (n.e.c.), electrical equipment, transport equipment, manufacturing non elsewhere classified (n.e.c.), and two other industries construction and hotels \& restaurants, which we thought were more appropriately included in this group. The second group comprises five network and service industries: energy, transport \& communication, retail distribution, banking services and professional services, which for simplicity we call Non-Manufacturing industries.

\section{A1.2 MultiFactor Productivity (MFP)}

Our regression model, referred as (1) in the text, is expressed in terms of MFP levels. These levels are calculated for a base year (2000) and then extended over the sample period using data on MFP growth calculated as follows (using small letters for logarithms):

$$
\Delta m f p_{c i t}=\Delta v a_{c i t}-\left(\alpha_{i} . \Delta l_{c i t}+\beta_{i} \cdot \Delta c_{c i t}^{I}+\gamma_{i} . \Delta c_{c i t}^{N I}+\Delta c_{c i t}^{S}+\theta_{i} \cdot \Delta k_{c i t}\right)
$$

where $V A_{\text {cit }}$ is the Value Added at constant price of country $c$, industry $i$ at time $t, L$ is the total employment in number of workers, $C^{I} C^{N I}$ and $C^{S}$ the physical capital stocks of, respectively, Information and communication technology (I), Non-ICT equipment (NI) and non-residential Structure (S), $K$ the Knowledge capital stock and $\alpha_{i}, \beta_{i}, \gamma_{i}$ and $\theta_{i}$ the output elasticity of these factors in industry $i$, approximated by the factor cost shares over total cost in the USA, averaged on the 1987-2007 period for each industry. Remember that regression (1) including country*industry fixed effects, our estimates of the impact parameters of interest are in fact independent of the MFP levels and relate only to MFP growth rates. Capital stocks $C^{I}, C^{N I}$ and $C^{S}$ and $K$ are calculated from investment data using the so called permanent inventory method, assuming constant 
geometric rates of depreciation: 5\% for non-residential structures, $10 \%$ for non-ICT equipment, $20 \%$ for ICT equipment and 25\% for R\&D. In order to compute investments at constant prices, we have used investment deflators at the national level. Because of the lack of specific price information for $R \& D$, we have used as a proxy the manufacturing production deflator. To improve comparability, we have assumed that in all countries for the ICT investments in hardware, software and telecommunications equipment the ratio of investment prices to the GDP price is the same as for the USA. This correction appears indeed as important since the USA is the country that uses most systematically hedonic methods to measure these prices and that the quality improvements have been considerable for these products during the study period. Data on value added and employment come from the OECD STAN database, data on R\&D expenses from the ANBERD OECD database and on physical investments for non-residential structures, non-ICT and ICT equipment from the EU KLEMS database. Since $R \& D$ is not yet treated as investment in the national accounts collected by OECD, we had to correct both the industry value added by adding ("expensing out") the intermediate consumption of their R\&D activities, and the industry number of employees by subtracting the number of R\&D personnel ("avoiding double counting"). Note also that we had to modify the price index of value added, and hence its value at constant prices, for the "Electrical and optical equipment" industry, which includes ICT equipment. We assumed as for ICT investment that in this industry the ratio of value added prices to the GDP price is the same in all countries as for the USA.

Figure A1.1. Country Box Plot of log MFP Growth

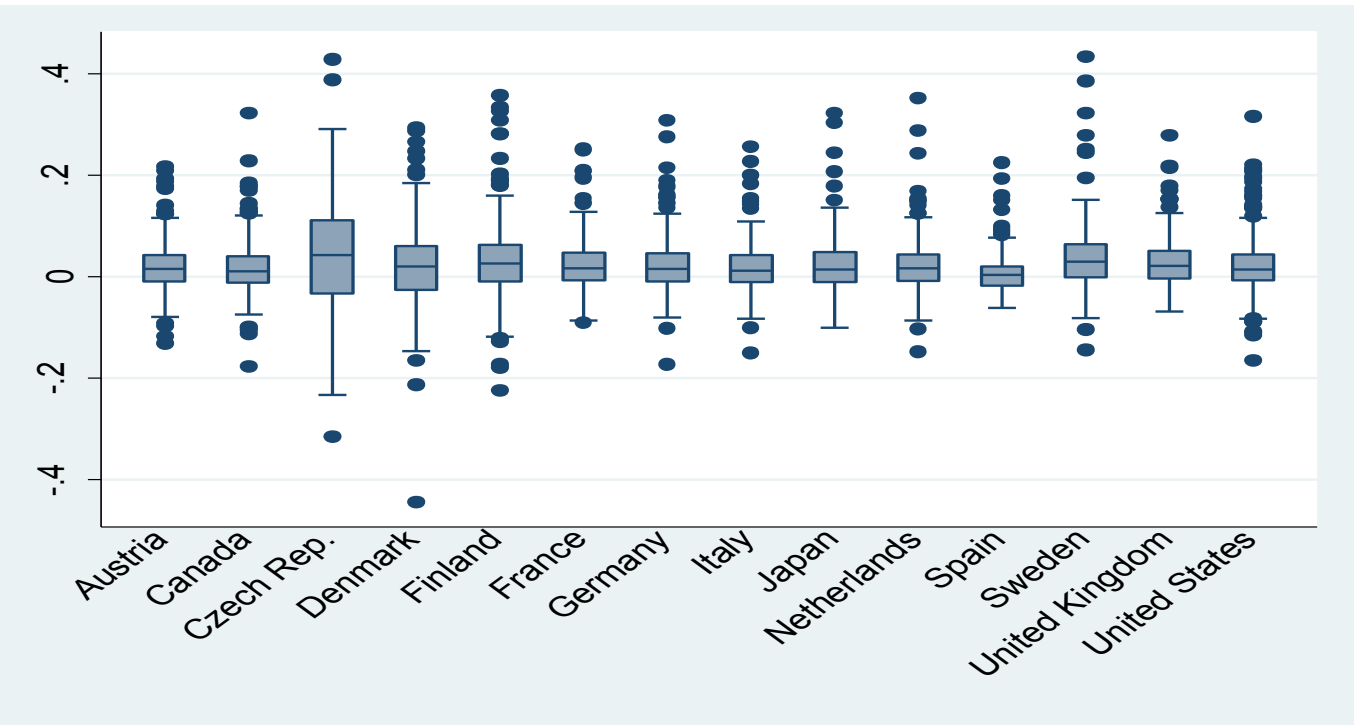

MFP growth rates $=\log \left(M F P_{t}\right)-\log \left(M F P_{t-1}\right)$ in percent

The country Box Plots of Figure A1.1 shows that MFP growth rates cannot only be widely varying from year to year and across industries, but that 
they also differ significantly in average by country, the median MFP growth i ranging from $0.35 \%$ in Spain and $1.01 \%$ in Canada to $2.97 \%$ and $4.28 \%$ in the Czech Republic.

\section{A1.3 Production Prices and Wages indexes}

In regression model (1), as explained in section II of the text, we have computed the price indicators of direct and indirect impacts with respect to manufacturing and non-manufacturing:

$$
D M \_p_{c i t}, D N M \_p_{c i t}, I M \_p_{c i t} \text { and } I N M \_p_{c i t}
$$

on the basis of the country*industry production prices indexes to the country GDP price index, which are available in the OECD STAN database. We have computed similarly the low and high-skilled wage indicators of impact:

$$
J L_{-} w_{c i t} \text { and } J H_{-} w_{c i t}
$$

using the country wage indexes relative to the country GDP price index, which come from the EUKLEMS database. As noted in the text, what we refer as low-skilled indicator $J L_{-} w_{c i t}$ is in fact combined with the medium- skilled indicator, with some gain of precision in estimation. The Bar chart of Figure A1.2 shows the manufacturing and non-manufacturing sample average annual growth rates of country production prices relative to GDP price. Except for Japan, all these growth rates relative to GDP price growth rate are negative, and quite limited in average per year. We see nonetheless significant differences across countries and a wider relative average decrease for manufacturing than for non-manufacturing industries.

Figure A1.2. Sample Average Annual Growth of Relative Production Prices

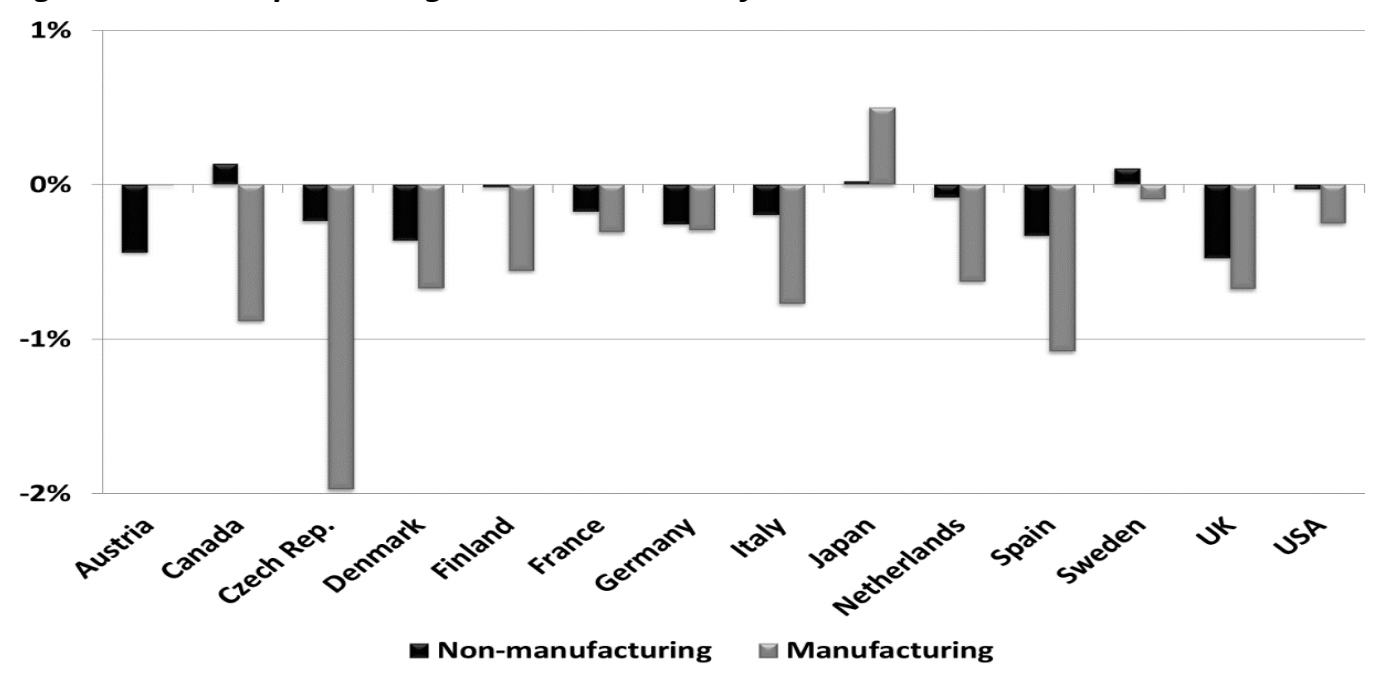

Similarly, the Bar chart of Figure A1.3 shows the sample average annual growth rate of real wages for high-skilled and low-skilled workers. 
Figure A1.2. Sample Average Annual Growth of Real wages, by Skill Level

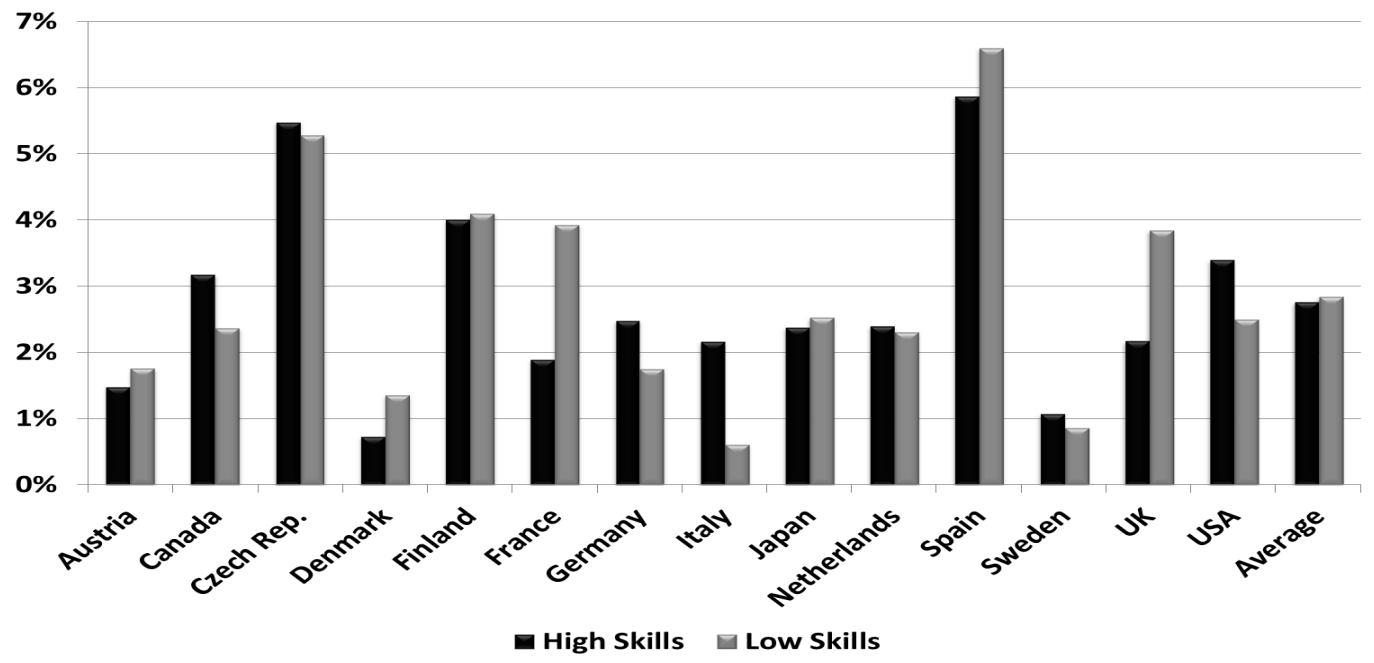

These growth rates are all positive and larger than for the production prices, but also differ markedly across countries in average per year. We also observe they are quite close for the low and high-skilled wages.

\section{A1.4 Variance Analysis}

We have explained in Section 3 of the text why, in addition to the necessary inclusion of country*industry fixed effects, we have included country*year fixed effects in estimating regression model (1), and why we did not also include industry* ${ }^{*}$ ear fixed effects. We also refer to Cette et al. (2016) to clarify why these two specifications tend to respectively provide upper and lower range estimates, which can be indeed verified in Tables 1 and 2. One important reason we put forward was the trade-off between exacerbating attenuation biases from errors in variables and correcting for omitted variables and stricto sensu endogeneity. Such trade-off mainly depends on the reduction of variability in the dependent and independent regression variables, which is resulting from introducing fixed effects and which can often be massive. Tables A1.1 and A1.2 show in detail how such reduction is increasing with the progressive introduction of fixed effects. The analysis of variance in Table A1.1 starts from the regression specification in levels with country*industry fixed effects that we privileged. The analysis of variance in Table A1.2 starts from a specification in first-differences that also control for country*industry fixed effects by first-differencing country* ${ }^{*}$ ear observations, but is more vulnerable to errors in variables than the fixed effect country*industry or "within country*industry" that we favor.

In both tables, each column gives the residual standard-deviation of the regression on a sequence of fixed effects for each of variables in our analysis. Thus in Table A1.1, column (1) shows the dispersion if we were including only the country, industry and year fixed effects $\eta_{c}, \eta_{i}, \eta_{t}$ while column (2) shows by how much this dispersion is reduced by also 
including the country*industry fixed effects $\eta_{c i}$ (which we have to do since all our variables are computed from country*industry indexes equal to 1 by construction in a given reference year).

Columns (3) and (4) document the further reductions in dispersion by including respectively the country*year fixed effects alone, which is our preferred specification, or both the country*year and industry*year fixed effects $\eta_{c t}$ and $\eta_{i t}$. We can observe that the residual standard deviations in column (3) are particularly small and that they are even smaller in column (4) for INM_p, the indirect price impact indicator with respect to non-manufacturing, and for $J L_{-} w$ and $J H_{-} w$, the low and high-skilled impact indicators.

This accounts for the relatively large standard errors of the corresponding estimated elasticities of our preferred estimates in column (6) of Table 1 in the text. It also accounts for the significant drop in these elasticities in column of Tables 1 and 2, which is probably related to the exacerbation of measurement errors biases.

Table A1.1. Analysis of Variance of the Regression Variables in log Levels Controlling Sequentially for Fixed Effects

\begin{tabular}{|c|c|c|c|c|c|}
\hline & & (1) & (2) & (3) & (4) \\
\hline \multirow{4}{*}{ Fixed effects } & Country, industry, year & $\mathrm{Y}$ & $\mathrm{Y}$ & $\mathrm{Y}$ & $\mathrm{Y}$ \\
\hline & Country*industry & $\mathrm{N}$ & $\mathrm{Y}$ & $\mathrm{Y}$ & $\mathrm{Y}$ \\
\hline & Country*year & $\mathrm{N}$ & $\mathrm{N}$ & $\mathrm{Y}$ & $\mathrm{Y}$ \\
\hline & Industry*year & $\mathrm{N}$ & $\mathrm{N}$ & $\mathrm{N}$ & $\mathrm{Y}$ \\
\hline \multicolumn{2}{|l|}{$M F P(m f p)$} & 0.235 & 0.162 & 0.163 & 0.079 \\
\hline \multicolumn{2}{|l|}{ US MFP (mfp $\left.p^{u s}\right)$} & 0.168 & 0.161 & 0.164 & $-*$ \\
\hline \multicolumn{6}{|l|}{ Direct prices in } \\
\hline \multicolumn{2}{|c|}{ Manufacturing industries (DM_p) } & 0.08 & 0.067 & 0.067 & 0.051 \\
\hline \multicolumn{2}{|c|}{ Non-Manuf. Industries (DNM_p) } & 0.042 & 0.031 & 0.03 & 0.028 \\
\hline \multicolumn{6}{|c|}{ Indirect prices from } \\
\hline \multicolumn{2}{|c|}{ Manufacturing industries (IM_p) } & 0.038 & 0.033 & 0.03 & 0.019 \\
\hline \multicolumn{2}{|c|}{ Non-Manuf. Industries (INM_p) } & 0.007 & 0.007 & 0.003 & 0.002 \\
\hline \multicolumn{6}{|c|}{ Country wages * industry labor share } \\
\hline \multicolumn{2}{|c|}{ High Skills (JH_w) } & 0.071 & 0.009 & 0.007 & 0.004 \\
\hline \multicolumn{2}{|c|}{ Low Skills (JL_w) } & 0.106 & 0.015 & 0.009 & 0.005 \\
\hline \multicolumn{2}{|c|}{ Degree of freedom } & 2766 & 2571 & 2433 & 2173 \\
\hline \multicolumn{2}{|l|}{ Observations } & 2820 & 2820 & 2820 & 2820 \\
\hline
\end{tabular}

*The variability in $\left(m f p^{U S}\right)$ is necessarily null when controlling for industry*year fixed effects. Columns (1), (2), (3) and (4) give the standard deviations of the variables after controlling for fixed effects.

Estimation in country*industry log first differences may be easier to interpret than estimation in within country*industry log levels, which is what we do in another way by including in the specification of regression (1) the country ${ }^{*}$ industry fixed effects $\eta_{c i}$. The columns (1), (2) and (3) of Table A1.2 thus correspond respectively to the columns (2), (3) and (4) of Table A1.1. We can indeed verify that the comparable evidence. Actually when we estimate regression (1) in country*industry log first differences, we obtain estimated elasticities that are not qualitatively different but that tend to smaller and have higher standard errors. In fact within level estimators have the advantage of being less affected by potential measure- 
ment errors in variables than estimators in first differences, which why we prefer the former in the present analysis (see Mairesse, 1990).

Table A1.2. Analysis of Variance of the Regression Variables in country*industry log Differences Controlling Sequentially for Fixed Effects

\begin{tabular}{|c|c|c|c|c|}
\hline & & (1) & (2) & (3) \\
\hline \multirow{2}{*}{ Fixed effects } & Country*year & $\mathrm{N}$ & $\mathrm{Y}$ & Y \\
\hline & Industry*year & $\mathrm{N}$ & $\mathrm{N}$ & $\mathrm{Y}$ \\
\hline \multicolumn{2}{|l|}{$M F P(m f p)$} & 0.066 & 0.064 & 0.052 \\
\hline \multicolumn{2}{|c|}{ US MFP (mfp $\left.p^{u s}\right)$} & 0.058 & 0.057 & $---*$ \\
\hline \multicolumn{5}{|c|}{ Direct prices in } \\
\hline \multicolumn{2}{|c|}{ Manufacturing industries (DM_p) } & 0.03 & 0.028 & 0.021 \\
\hline \multicolumn{2}{|c|}{ Non-Manuf. Industries (DNM_p) } & 0.018 & 0.018 & 0.018 \\
\hline \multicolumn{5}{|c|}{ Indirect prices from } \\
\hline \multicolumn{2}{|c|}{ Manufacturing industries (IM_p) } & 0.016 & 0.011 & 0.008 \\
\hline \multicolumn{2}{|c|}{ Non-Manuf. Industries (INM_p) } & 0.004 & 0.002 & 0.002 \\
\hline \multicolumn{5}{|c|}{ Country wages * industry labor share } \\
\hline \multicolumn{2}{|c|}{ High Skills (JH_w) } & 0.004 & 0.003 & 0.002 \\
\hline \multicolumn{2}{|c|}{ Low Skills (JL_w) } & 0.007 & 0.003 & 0.003 \\
\hline \multicolumn{2}{|c|}{ Degree of freedom } & 2590 & 2432 & 2172 \\
\hline \multicolumn{2}{|l|}{ Observations } & 2591 & 2591 & 2591 \\
\hline
\end{tabular}

*The variability in $\left(m f p^{U S}\right)$ is necessarily null when controlling for industry*year fixed effects. Column (1) gives the standard deviations of the first difference of the variables, while columns (2) and (3) gives them after controlling respectively for country*year fixed effects and both country*year and industry*year fixed effects.

\section{Appendix 2 OECD Regulation Indicators}

In this Appendix, we present shortly the OECD regulation indicators on which we rely to calibrate our manufacturing and non-manufacturing production prices indicators and our low and high-skill wages indicators. They are precisely: 1) the Non-Manufacturing Regulation (NMR) indicators (available for five non-manufacturing industries), 2) the Harmonized Tariffs (HT) indicators, available for manufacturing industries, and the Foreign Direct Investment (FDI) restrictiveness indicators for the construction and hotels \& restaurants, 3) and the Employment Protection Legislation $(E P L)$ indicators.

\section{A2.1 NMR Indicators}

The OECD NMR indicators measure the extent to which competition and firm choices are restricted where there are no a priori reasons for government interference, or where regulatory goals could plausibly be achieved by less coercive means. They are based on detailed information on laws, rules, market and industry settings and cover energy (gas and electricity), transport (rail, road and air) and communication (post, fixed and cellular telecommunications), retail distribution and professional 
services (see Conway and Nicoletti, 2007, for a more detailed presentation). ${ }^{8}$

The Bar chart in Figure A2.1 documents the values of the NMR indicators and the corresponding lightest regulation practices for 2013. ${ }^{9}$ The year 2013 is the one chosen to construct the lightest regulatory practices taken as target of the ex-ante policy simulation presented in the text. ${ }^{10} \mathrm{We}$ observe differences that can be very important both between country and within country across the four non-manufacturing industry regulations.

Figure A2.1. OECD Non-Manufacturing Regulation (NMR) Indicators in 2013

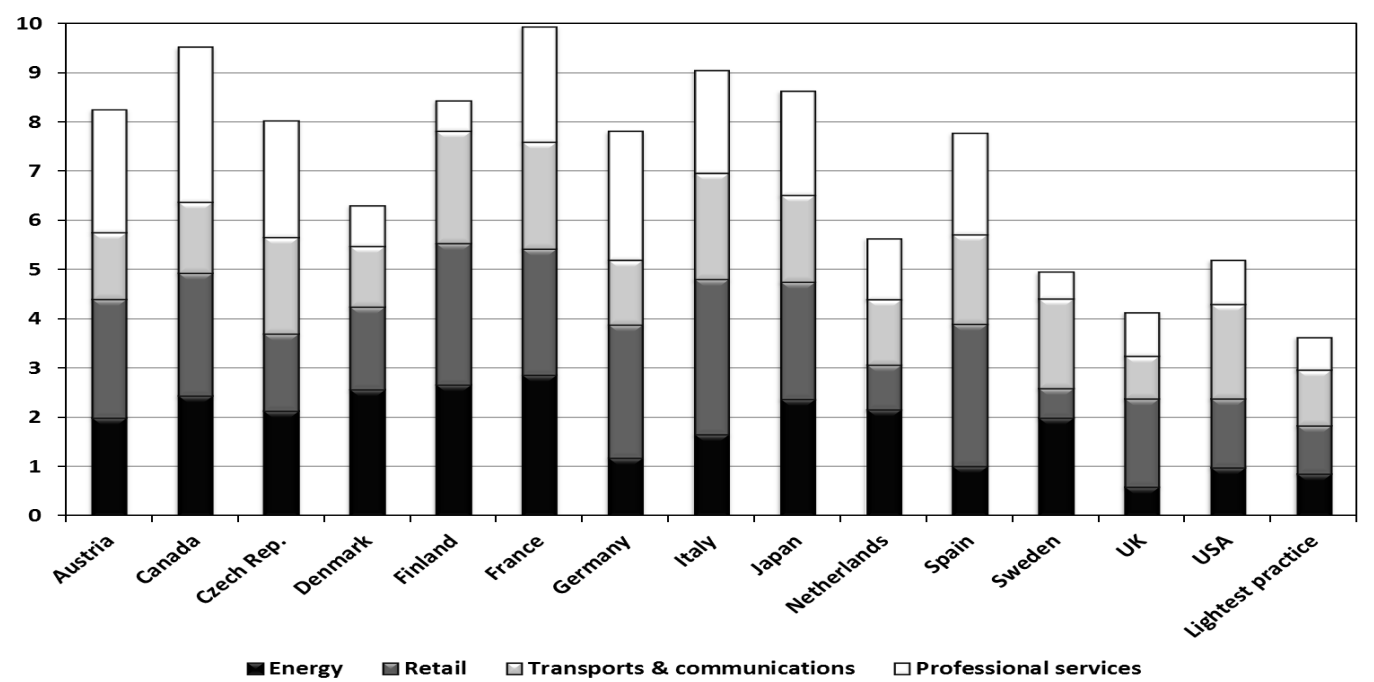

Scale 0-6 for each indicator, 0 for the most pro-competitive

\section{A2.2 HT and FDI Indicators}

The OECD Harmonized Tariff (HT) indicators are computed on the basis of the ad valorem tariff rates applied to the most favored nation at the six-digit level of the Harmonized System Product Classification. They are aggregated into indicators using import-based weights at the two-digit (ISIC Rev. 3) industry level. These indicators are coded between zero and six with zero for the smallest tariffs (see Nicoletti and Scarpetta, 2003, for a more detailed presentation).

Since no HT indicators do not exist for the 'Construction' and 'Hotels and restaurants' industries, we use for them the OECD Foreign Direct Investment $(F D I)$ restrictiveness indicators. These indicators measure

8 Note that we cannot include banking and financial services in our analysis, since the indicator of regulatory restrictions for this industry has been constructed by Serres et al. (2006) only for the year 2003.

9 Note that the 2013 OECD NMR indicators take into account new questions. Using the updates provided by OECD results in insignificant changes in our estimation results.

10 However, note that, since the HT indicators are not available after 2007, we have simply assumed they remain constant afterwards for the purpose of our calibration and ex-ante simulation. 
different forms of discrimination against foreign firms, such as i) restrictions on foreign ownership, i.e. limitations of the share of companies' equity capital in a particular sector that are not applied to domestic firms; ii) obligatory screening and approval procedures for foreign affiliates; iii) operational constraints or controls for affiliates of foreign companies, including constraints to the mobility of foreign professionals working in these affiliates. They are primarily based on information from the GATS Commitments and country submissions to the OECD Code of Liberalization of Capital Movements (see Koyama and Golub, 2006, for a more detailed presentation).

The Bar chart in Figure A2.2 records the HT and FDI indicator values in 2007 (the last year for which the HT indicator information is available), as well as the corresponding values of the lightest regulation practices. As in the case of the NMR indicator values, we observe major differences between country and within country across industry. We see in particular that harmonized tariffs are very high in the food products (ISIC code 15-16) and in the textiles (17-19), with significant differences between countries.

Figure A2.2. OECD Harmonized Tariff (HT) and Foreign Direct Investment (FDI) Indicators in 2007, by Country-industry

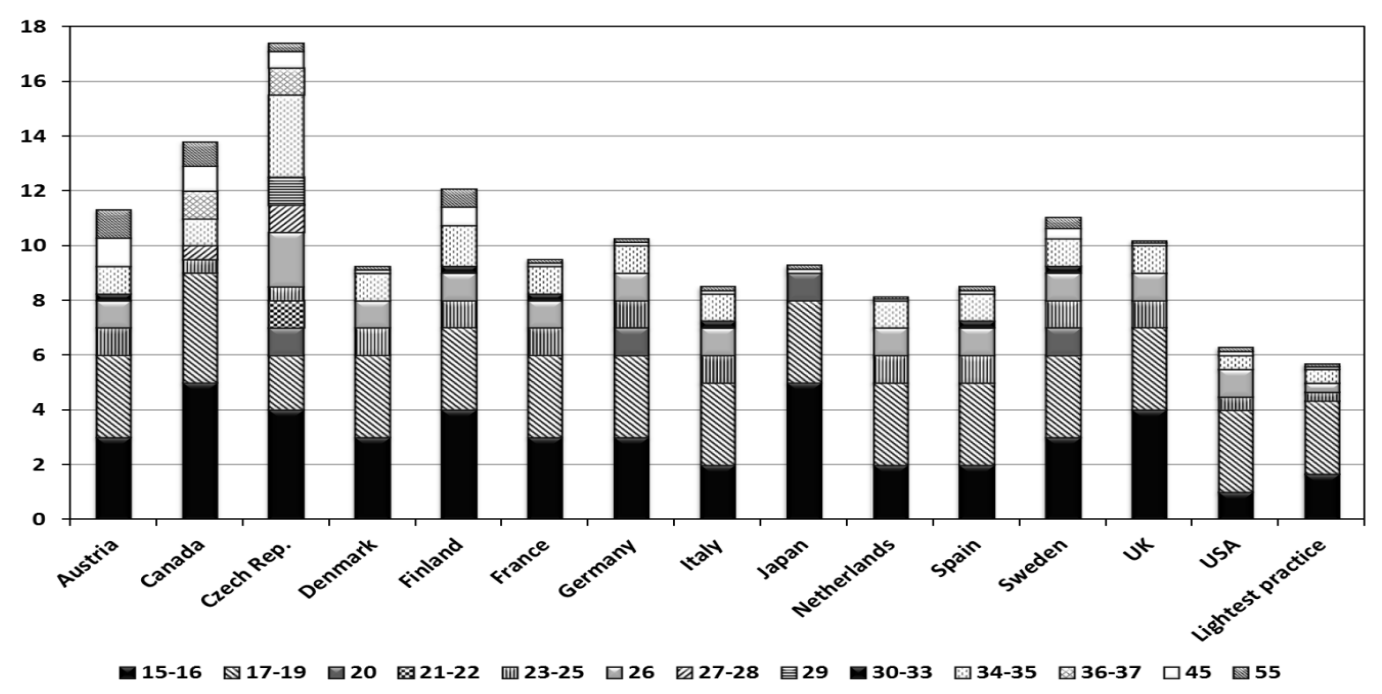

Scale 0-6 for each industry, 0 for the smallest tariffs. The 2-digit (ISIC Rev. 3) industries (with their codes in parentheses) codes are the following: food products (15-16), textiles (17-19), wood products (20), paper (21-22), chemicals products (23-25), non-metallic mineral products (26), metal products (27-28), machinery n.e.c. (29), electrical equipment (30-33), transport equipment (34-35), manufacturing n.e.c. (36-37), construction (45) and hotels \& restaurants (55).

\section{A2.3. EPL Indicators}

The OECD provides various labor market regulation indicators: unemployment replacement rates, expenditures on labor market programs, statutory minimum wages, union members and Employment Protection Legislations (EPL). Bassanini and Venn (2008) provide an 
empirical analysis of the impact of these various indicators on productivity.

Our analysis focuses on the EPL indicators, which are the most frequently used in the empirical literature on the impact of labor market regulations on productivity and growth. Like the NMR indicators, the EPL indicators are based on detailed information on laws, rules and market settings. They measure the procedures and cost involved in dismissing individual workers with regular contracts (data on collective dismissal is available only since 1998) and regulations on temporary contracts, including regulations on fixed-term and temporary work agency contracts (see OECD Employment Outlook 2013 for more information).

The Bar chart in Figure A2.3 shows the values of EPL on regular and on temporary contracts in 2013 as well as the lightest practice. We observe that are higher in continental European countries relatively to the other countries, and particularly as concerns regular contracts.

Figure A2.3. OECD Employment Protection Legislation (EPL) indicators in 2013

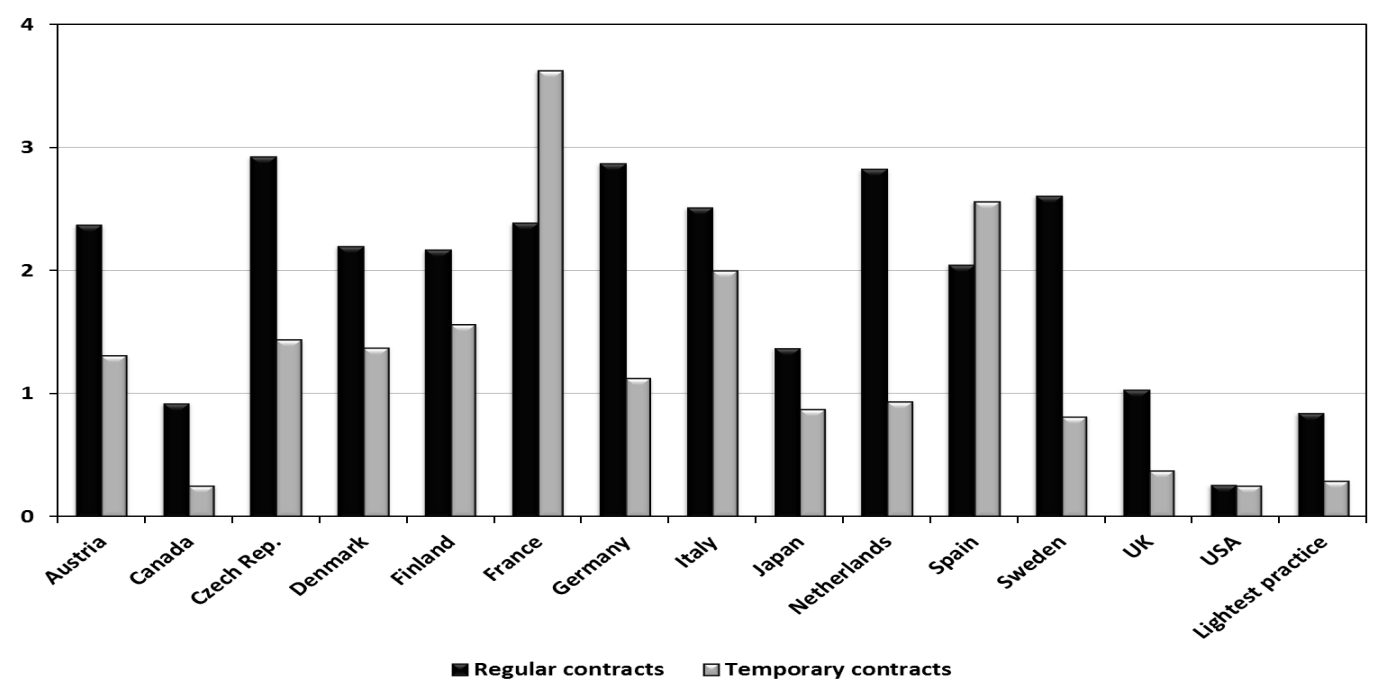

\section{Appendix 2 References}

Bassanini, A., Venn, D., 2008. The Impact of Labour Market Policies on Productivity in OECD Countries. International Productivity Monitor 17, 3-15.

Conway, P., Nicoletti, G., 2007. Product Market Regulation and Productivity Convergence: OECD Evidence and Implications for Canada. International Productivity Monitor 15, 3-24.

De Serres, A., Kobayakawa, S., Slok, T., Vartia, L., 2006. Regulation of Financial Systems and Economic Growth in OECD Countries: An Empirical Analysis. Organisation for Economic Co-operation and Development (OECD) Economic Studies 43, 77-113. 
Koyama, T., Golub, S., 2006. OECD's FDI Regulatory Restrictiveness Index: Revision and Extension to more Economies. Organisation for Economic Co-operation and Development (OECD) Working Papers 525.

Nicoletti, G., Scarpetta, S., 2003. Regulation, Productivity and Growth. Economic Policy 36, 11-72.

Organisation for Economic Co-operation and Development (OECD), 2013. Employment Outlook 2013. OECD Publishing, Paris.

\section{Appendix 3. Ex-post Simulation from 2008-2013 Regulatory Changes and Assessment of the Dynamic Adjustment}

\section{A3.1 Ex-post Simulation from 2008-2013 Regulatory Changes}

We have based our ex-post simulation only on the evidence provided by the OECD. NMR and EPL indicators, since the HT indicators are not available after 2008 (as noted in footnote six in the text). We have not also been able to include in our simulation the USA, since the HT indicators is also lacking too for 2008 for this country. The Bar chart in Figure A3.1 documents what have been the changes in these indicators over the period 2008-2013.

Figure A3.1. OECD NMR and EPL Indicators Changes over 2008-2013 Period

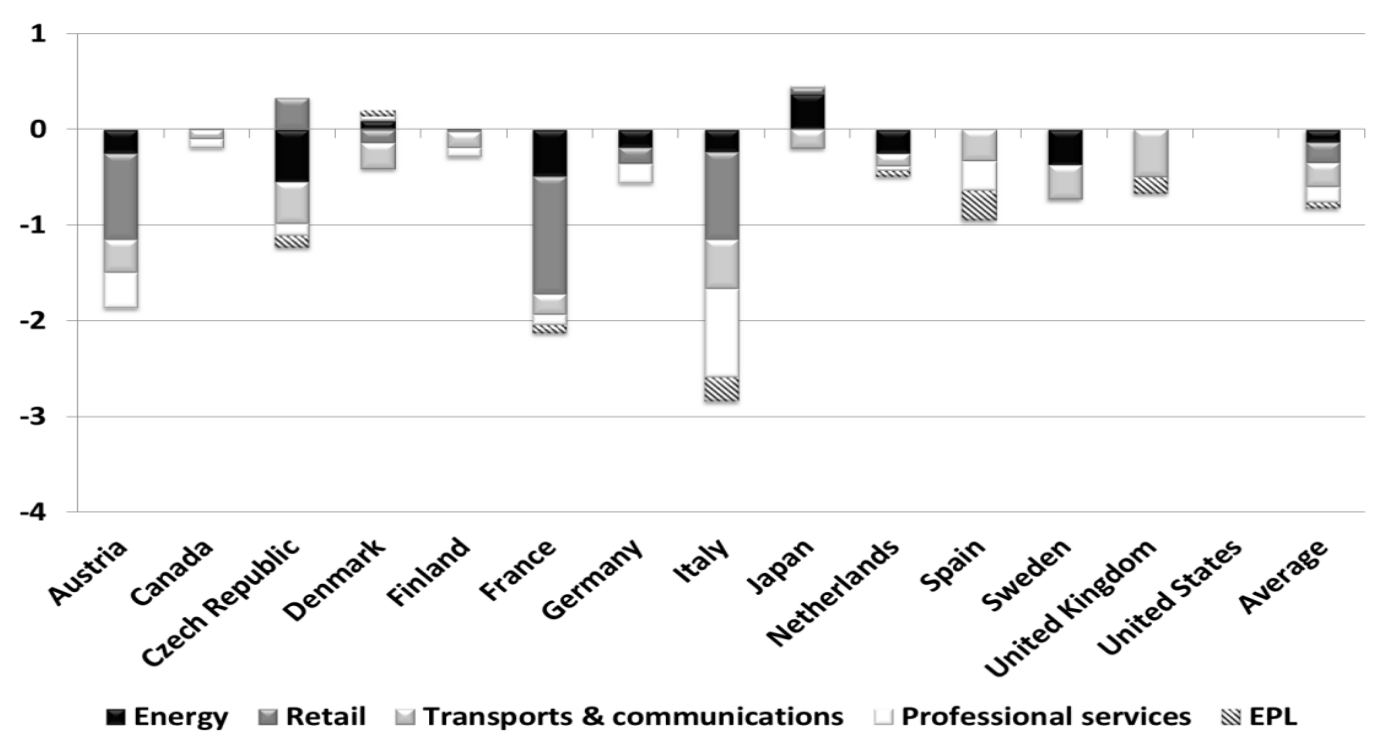

Scale of the indicators in levels: 0-6, 0 for the most pro-competitive level.

The Bar chart in Figure A3.2 shows the long-term MFP gains that can be expected from these regulatory changes. It is similar to Figure 2 in the text for the expected long-term MFP gains under the extreme hypothesis of an 
immediate implementation in all countries of the 2013 lightest regulatory practices. The evaluation method is the same in the two cases as explained in Section 4 of the text. We have simply aggregated the country*industry estimated MFP gains at the country level by weighting them by the value added industry shares in national GDP. The differences in long-term MFP gains across countries are thus directly related to the differences in the changes in NMR and EPL regulatory reforms. The estimated MFP gains are highest for Italy, then France and Austria. It is important to keep in mind, however, that these are long term expected gains, and that on the basis of our rough assessment of adjustment speed we can consider that only about $20 \%$ to $30 \%$ of these gains have possibly been achieved as of 2014.

Figure A3.2. Simulated Long-term MFP Gains Expected from the NMR and EPL Regulatory Changes over 2008-2013.

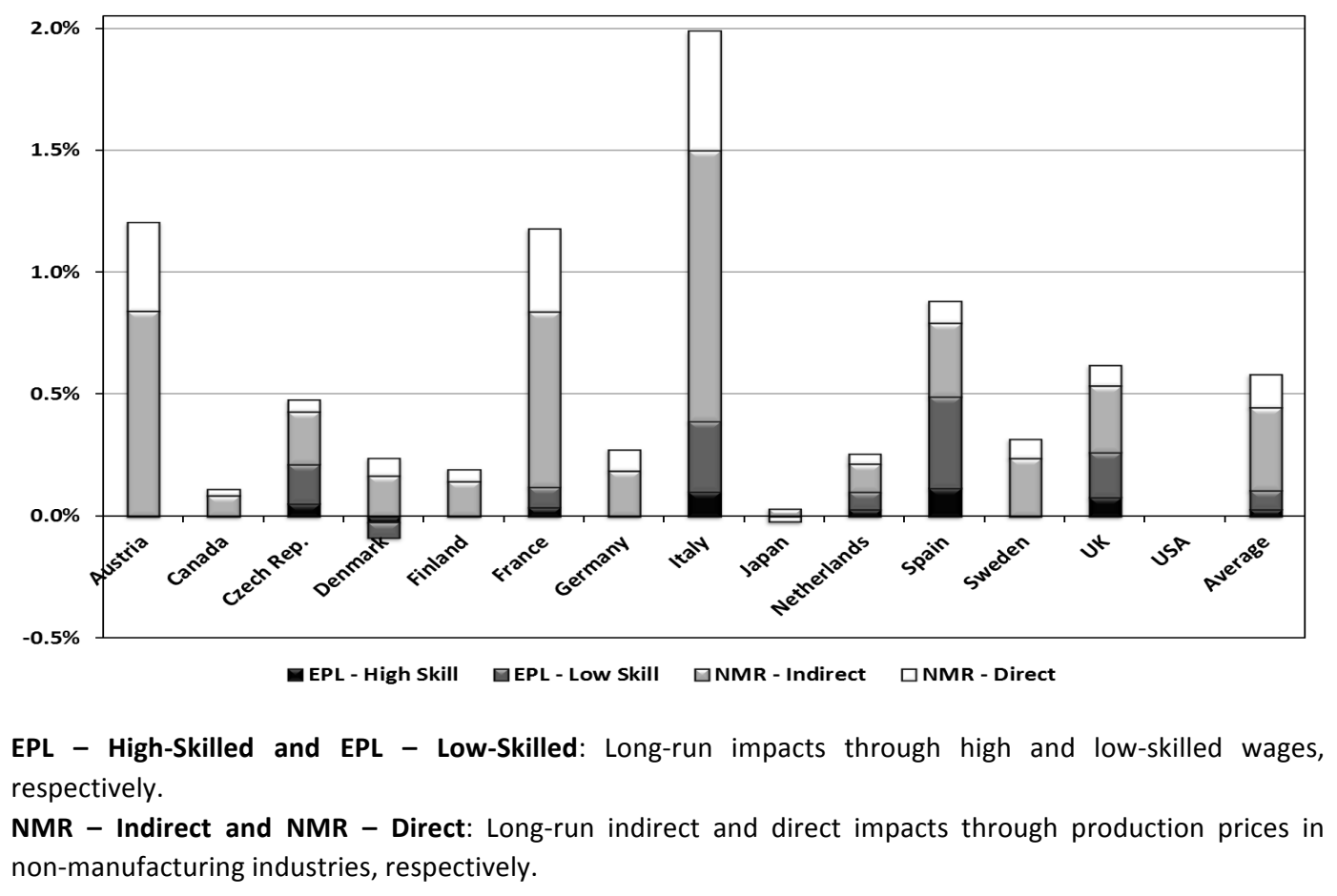

\section{A3.2 Assessment of the Dynamic Adjustment}

The DOLS estimator presented in section IV provides the long-term coefficients of the estimated relationships. To assess the dynamic path of impacts of the reforms, we rely on simple error-correction regressions and proceed in two steps. First, we compute the error-correction terms, noted EC, as the differences between the current values of our dependent variables ( $D M_{-} p, D N M_{-} p, I M_{-} p, I N M_{-} p, J H_{-} w, J L_{-} w$, and $\left.m f p\right)$ and their long-term prediction. ${ }^{11}$ Then, we regress, the observed first differences in

11 Note that this difference would be equal to the residual of the long-term estimation if we used OLS, but this not anymore the case with DOLS. 
these variables (with $\Delta$ indicating a first difference) on the corresponding lagged error-correction terms:

$$
\begin{gathered}
\Delta D N M_{-} p_{c i t}=\pi^{a} \cdot C E_{c i t-1}^{a}+\epsilon_{c i t}^{a} \\
\Delta D M_{-} p_{c i t}=\pi^{b} \cdot C E_{c i t-1}^{b}+\epsilon_{c i t}^{b} \\
\Delta J H_{-} w_{c i t}=\pi^{c} \cdot C E_{c t-1}^{c}+\epsilon_{c t}^{c} \\
\Delta J L_{-} w_{c i t}=\pi^{d} \cdot C E_{c t-1}^{d}+\epsilon_{c t}^{d} \\
\Delta m f p_{c i t}=\pi^{p g f} \cdot C E_{c i t-1}^{m f p}+\epsilon_{c i t}
\end{gathered}
$$

Table A3.1 presents the corresponding estimation results. As expected, a positive error-correction term has a negative and significant impact on the growth of production prices, real wages and multifactor productivity.

Table A3.1. Dynamic Adjustment Calibration Relationships

\begin{tabular}{lccccc}
\hline \multirow{2}{*}{$\begin{array}{c}\text { Dependent } \\
\text { variable }\end{array}$} & $\begin{array}{c}\text { MFP growth } \\
(\Delta \mathbf{m f p})\end{array}$ & \multicolumn{2}{c}{$\begin{array}{c}\text { Relative production price growth } \\
(\Delta \mathbf{p})\end{array}$} & \multicolumn{2}{c}{ Real wage growth $(\Delta \mathbf{w})$} \\
& & Non-manuf. & Manuf. & High-skilled & Low-skilled \\
\cline { 2 - 6 } & $\mathbf{( 1 )}$ & $\mathbf{( 2 )}$ & $\mathbf{( 3 )}$ & $\mathbf{( 4 )}$ & $\mathbf{( 5 )}$ \\
Error Correction & $-0.215^{* * *}$ & $-0.235^{* * *}$ & $-0.025^{* *}$ & $-0.119^{* * *}$ & $-0.066^{* *}$ \\
term (EC) & {$[0.013]$} & {$[0.027]$} & {$[0.010]$} & {$[0.036]$} & {$[0.033]$} \\
Observations & 2820 & 753 & 2067 & 225 & 225 \\
R-squared & 0.095 & 0.088 & 0.004 & 0.056 & 0.039 \\
\hline
\end{tabular}

*** significant at $1 \% ;{ }^{* *}$ significant at $5 \%$; ${ }^{*}$ significant at $10 \%$. Standard errors between brackets. 